\title{
VARIAÇÃO SAZONALDA POPULAÇÃO DE BACTÉRIAS E FUNGOS E DOS TEORES DE NITRATO E AMÔNIO DO SOLO NOS SÍTIOS DO LBA E PPBIO, NA AMAZÔNIA ORIENTAL
}

\author{
Quêzia Leandro de Moura ${ }^{1}$, Maria de Lourdes Pinheiro Ruivo ${ }^{2}$, Hernani José Brazão Rodrigues ${ }^{3}$, Edson José \\ Paulino Rocha ${ }^{3}$, João de Athaydes Silva Junior ${ }^{3}$, Steel Silva Vasconcelos ${ }^{4}$, Mariseth Carvalho Andrade ${ }^{5}$, \\ Carmem-Lara de Oliveira Manes ${ }^{6}$ \\ ${ }^{1}$ Universidade Federal do Oeste do Pará, Santarém, Pará, Brasil \\ ${ }^{2}$ Museu Paraense Emílio Goeldi, Belém, Pará, Brasil \\ ${ }^{3}$ Universidade Federal do Pará, Instituto de Geociências, Faculdade de Meteorologia, Belém, Pará, Brasil \\ ${ }^{4}$ Empresa Brasileira de Pesquisa Agropecuária (EMBRAPA), Belém, Pará, Brasil \\ ${ }^{5}$ Centro Universitário do Estado do Pará, Belém, Pará, Brasil \\ ${ }^{6}$ Instituto Tecnológico Vale (ITV), Belém, Pará, Brasil
}

queziamoura@hotmail.com,ruivo@museu-goeldi.br,hernani@ufpa.br,eprocha@ufpa.br, athaydes@ufpa.br, steel.vasconcelos@embrapa.br,marisethandrade@cesupa.br,carmem.manes@vale.com

Recebido Julho de 2014 - Aceito Fevereiro de 2015

\begin{abstract}
RESUMO
É possível que os fatores ambientais, que determinam o comportamento da microbiota edáfica, estejam sendo modificados pelas mudanças climáticas de origem natural e/ou antrópica. A fim de verificar o efeito da exclusão de água sobre a população de bactérias e fungos do solo, foi desenvolvido o presente estudo na área do experimento ESECAFLOR, que simula a ocorrência de fenômenos extremos, como o evento El Niño, e na área do Programa de Pesquisa em Biodiversidade - PPBio (Floresta Primária), que visa estudar a Biodiversidade da Amazônia, sendo esta usada como controle para fins comparativos. As amostras de solo foram coletadas nas profundidades: 0-5, 5-10, 10-20 e 20-30 cm, nos períodos sazonais chuvoso, de transição e menos chuvoso. Os maiores valores de Unidades Formadoras de Colônias (UFC) para as populações de Bactérias e Fungos foram $196 \times 10^{4}$ UFC/g de solo e $124 \times 10^{2} \mathrm{UFC/g}$ de solo, respectivamente, ambos na área sem intervenção antrópica (PPBio). A umidade do solo é a variável que teve maior influência nos valores nas contagens obtidas das populações de fungos e bactérias.
\end{abstract}

Palavras-chave: Estresse hídrico, Microrganismos, Floresta e Microclima.

ABSTRACT: SEASONAL VARIATION OF BACTERIA AND FUNGI POPULATIONS AND IN THE CONCENTRATIONS OF NITRATE AND AMMONIUM IN THE SOIL OF LBAAND PPBIO SITES, IN EASTERN AMAZON

It is possible that the environmental factors determining the behavior of soil microbiota are being modified by anthropic or natural climate change. In order to check the effect of the exclusion of water over the population of bacteria and fungi in the soil, the present study was developed. The chosen location is the area of the ESECAFLOR experiment, which simulates the occurrence of extreme phenomena such as El Niño event, and the area of biodiversity research program Program-PPBio (primary forest). This later area, supposed to be used for studying the Biodiversity of the Amazon, was used as a control area for comparative purposes. The soil was sampled at $00-05,05-10,10-20$ and 20-30 cm depths, during the rainy, transition and less rainy seasons. The highest values of Colonies Forming Units (CFU) for bacteria and fungi populations were $196 \times 10^{4} \mathrm{CFU} / \mathrm{g}$ of soil and $124 \times 10^{2}$ $\mathrm{CFU} / \mathrm{g}$ of solo, respectively, both in the area without human intervention (PPBio). Soil moisture is the variable influencing most the obtained counting values of fungi and bacteria populations.

Keywords: Water stress, Seasonal variations, Microorganisms, Forest, Microclimate. 


\section{INTRODUÇÃO}

A disponibilidade potencial dos nutrientes no solo é influenciada pela ação antrópica e microbiana, uma vez que essas devolvem ao ambiente os elementos como nitrogênio, potássio, fósforo que estavam retidos na matéria orgânica, e que são essenciais para o desenvolvimento das plantas. Nesse sentido, a atividade microbiana é considerada um componente edáfico que influencia na fertilidade do solo (Luizão, 1989; Novais e Barros, 1997; Furtini Neto, 2005).

É possível que o equilíbrio da biosfera esteja sendo modificado pelas mudanças globais de origem natural e/ou antrópica (Nobre et al. 2007, Fisher et al., 2007; Luizao, 2007; Marengo et.al.,2009; Fearnside, 2009; Costa et al., 2009). As variáveis como precipitação, temperatura e umidade do solo, são as mais relevantes no que se refere às mudanças metabólicas dos microorganismos (Chapin et al, 2002; Goberna et al., 2005; Moreira e Siqueira, 2006).

Os estudos realizados por Ruivo et al. (2002; 2006), Amarante et al. (2010), Vianal et al. (2010), Silva et al. (2010) e Rodrigues et al. (2011) identificaram alterações da atividade microbiana do solo conforme as mudanças dos fatores ambientais na região amazônica. Porém, ainda existem muitas perguntas a serem respondidas, e a quantidade de trabalhos que analisam a natureza, multiplicação, quantidade e atividade microbiana em função dos fatores abióticos são incipientes diante da diversidade e dinâmica microbiológica, estimada para os solos amazônicos.

A presente pesquisa teve como objetivo estudar o efeito da temperatura e da umidade de solo submetido ao estresse hídrico sobre a variação da população microbiana na Floresta Nacional de Caxiuanã.

\section{MATERIAL E MÉTODOS}

\subsection{Locais de estudo}

A Floresta Nacional (FLONA) de Caxiuanã está localizada na Amazônia Oriental, especificamente no Estado do Pará, e abriga ecossistemas que são típicos da Amazônia, como Terra Firme, Várzea e Igapó, os quais são riquíssimos em espécies vegetais (Almeida et al., 1993). A região foi desenvolvida em um baixo planalto formado durante o período Cretáceo e apresenta sedimentos quartzo-caoliníticos correlacionados à Formação Alter do Chão. O tipo de solo que ocorre com mais frequência são os Latossolos, porém Planossolos, Gleissolos e Terra Preta Arqueológica (TPA) já foram registrados para algumas áreas (Kern, 1996; Costa et al., 2009).

Segundo Silva Junior et al. (2013), o tipo de clima da região, com base na classificação de Köppen, é tropical quente e úmido e tipo climático "Am" com uma curta estação seca, com uma temperatura média do ar anual de $25,7 \pm 0,8{ }^{\circ} \mathrm{C}$, e uma pluviosidade média anual entorno de $2.272 \pm 193 \mathrm{~mm}$, com uma sazonalidade bem definida, sendo um período chuvoso compreendido de dezembro a maio $(1.717 \mathrm{~mm}$, representando $75,6 \%$ da pluviosidade anual), e um período menos chuvoso entre junho e novembro (555 $\pm 116 \mathrm{~mm}$, representando $24,4 \%$ da precipitação anual).

O presente estudo foi desenvolvido no ano de 2009, nas áreas experimentais do Programa de Pesquisa em Biodiversidade - PPBio, e na área do ESECAFLOR, projeto ligado ao Programa em Larga Escala da Biosfera-Atmosfera na Amazônia (LBA), conforme ilustrado na Figura 1.

O Programa de Pesquisa em Biodiversidade (PPBio) do Ministério de Ciência e Tecnologia, foi criado em 2004 e objetiva gerar, integrar e disseminar informações sobre biodiversidade que possam ser utilizadas para diferentes finalidades, em especial para a conservação dos ecossistemas amazônicos (INPA, 2007). O sitio do PPBio em Caxiuanã possui $25 \mathrm{~km}^{2}$ divididos em 30 parcelas permanentes de $250 \mathrm{x}$ $40 \mathrm{~m}$. $\mathrm{O}$ acesso às parcelas é realizado por 12 trilhas de $5 \mathrm{~km}$ de comprimento.

O LBA - Experimento em Grande Escala da BiosferaAtmosfera na Amazônia é um programa multinacional e interdisciplinar que visa estudar as interfaces entre o clima, o solo, os gases atmosféricos e os impactos do uso da terra

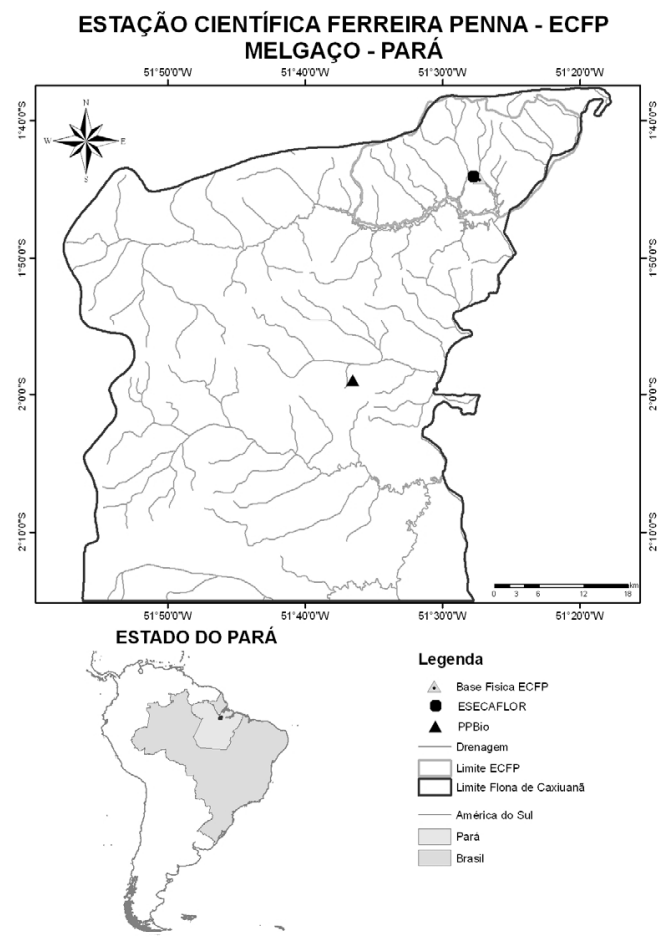

Figura 1: Localização da área de estudo. Fonte: Rodrigues et al. (2011) 
na Amazônia. No âmbito desse programa é desenvolvido o experimento ESECAFLOR - O Impacto da Seca Prolongada nos Fluxos de Água e de $\mathrm{CO}_{2}$ em Floresta Tropical Amazônica, que consiste na indução de um período de seca na floresta para investigar os seus impactos nos diversos subsistemas de um ecossistema de Terra Firme em longo prazo (Meir et al., 2003; Costa et al., 2009). O ESECAFLOR é dividido em duas parcelas (A e B) de 1 ha cada. A parcela A é usada como testemunha para os experimentos implantados na parcela $\mathrm{B}$, onde há a exclusão de aproximadamente $80 \%$ das águas pluviais por meio da instalação de 6.000 painéis de madeira revestidos com plástico transparente a uma altura variando 1,5 a $4 \mathrm{~m}$ acima do solo. As parcelas possuem duas torres metálicas de $30 \mathrm{~m}$ de altura para a medição dos elementos meteorológicos (Costa et al., 2009).

A escolha dos pontos de coleta das amostras de solo foi determinada pela localização dos sensores eletrônicos destinados a leitura da temperatura e umidade do solo, instalados em cada área experimental. Com base em uma série histórica com 34 anos de registros precipitação pluvial da região, pertencente à Agência Nacional de Águas, se escolheu para a amostragem do solo os meses de março, setembro e julho, os quais melhor representam, respectivamente, a época chuvosa, a menos chuvosa e o período de transição das chuvas, conforme ilustrado na Figura 2.

As amostras de solo foram coletadas, com o auxílio de pás, por meio de trincheiras fixas de 30 x 50 escavadas em cada área de amostragem (três trincheiras na parcela CI - PPBio e três trincheiras na parcela B - ESECAFLOR), de onde foram coletadas amostras de solos nas profundidades: 0-05, 05-10, 10-20 e 20-30 cm em todos os meses supracitados. Foram coletadas quatro amostras (correspondente as faixas de profundidade) em cada trincheira, obtendo-se o esquema amostral de 4 (faixas de profundidade) X 3 (trincheiras) $\mathrm{X}$ 2 (áreas amostrais) X 3 (períodos sazonais), totalizando 72 amostras. Todas as amostras, no momento da coleta, foram acondicionadas em sacos plásticos estéreis, identificadas e, posteriormente, armazenadas em geladeiras.

Os dados de temperatura do solo nas profundidades de $5,10,20$ e $30 \mathrm{~cm}$, foram obtidos com o auxílio de sensores de temperatura, modelo 107-L da Campbell Scientific (-35 a $55^{\circ} \mathrm{C}$ ) e os valores do conteúdo volumétrico de água foram registrados por sensores de água no solo modelo C616-L da Campbell Scientific, que abrangeram as profundidades 0-30 $\mathrm{cm}$. Os dados foram registrados diariamente, a cada $30 \mathrm{~min}$, e armazenados em sistema de aquisição de dados, em ambos os sítios experimentais, de forma simultânea e com as mesmas especificações supracitadas.

Os valores de precipitação pluviométrica e temperatura do solo, referentes à área do PPBio, foram obtidos na estação meteorológica montada em área de clareira próxima a parcela CI do PPBio, e os dados representativos da área onde está implantado o experimento ESECAFLOR foram coletados na estação meteorológica montada na torre do Programa LBA localizada próximo a área experimental .

A quantificação das populações de bactérias e fungos foi realizada no Laboratório de Microbiologia da Universidade Estadual do Pará (UEPA). Para determinar a quantidade de Unidades Formadoras de Colônias - UFC de fungos e bactérias nas amostras de solo foi utilizado o método da incorporação ao meio descrito por Clark (1965), que consistiu basicamente na deposição da alíquota (solo e água) no interior da parte basal de uma placa de Petri estéril e posterior adição de meio de cultura (Martin, para fungos e Agar nutriente para bactérias). Após solidificação do meio, as placas foram incubadas por 2 dias em estufa com temperatura de $35^{\circ} \mathrm{C}$, no caso das bactérias, e por 5 dias em geladeiras com temperatura de $25^{\circ} \mathrm{C}$, para os fungos.

Antes do processo de inoculação, foi realizada uma diluição em série até a $4^{\circ}$ ordem, no caso das bactérias e até a $2^{\circ}$ ordem, no caso dos fungos. As amostras foram analisadas em

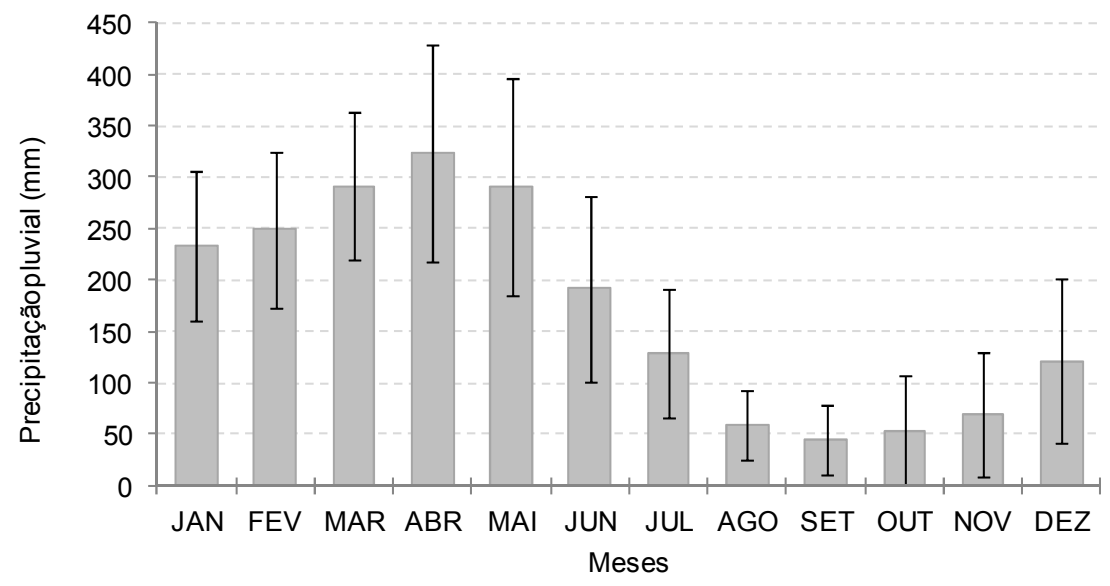

Figura 2: Série histórica de precipitação pluvial da Floresta Nacional de Caxiuanã, com seus respectivos desvios padrões. 
triplicata. A contagem das colônias foi realizada com o auxílio do contador de colônias modelo CP-602, em contraste com o meio ppaco de cultura. Os valores obtidos foram expressos em $10 \mathrm{UFC} / \mathrm{g}$ de solo para fungos e $10 \mathrm{UFC} / \mathrm{g}$ de solo para bactérias.

O extrato do solo para a determinação dos teores de nitrato e amônio conforme descrição realizada, respectivamente, por Yang et al. (1998) e Keeney (1982), foram obtidos com solução $2 \mathrm{~mol} \mathrm{~L}^{-1} \mathrm{KCl}$.

Aplicou-se uma análise estatística nos dados coletados com base no método ANOVA, com dois critérios para verificar as diferenças entre as áreas comparadas, as profundidades e os períodos sazonais estudados. Quando encontrada significância $(5 \%)$, as médias de cada parâmetro eram testadas pelo teste Tukey a $5 \%(p<0,05)$. A fim de identificar a correlação da população de bactérias e fungos com a temperatura, umidade e as variáveis químicas do solo foi realizado o teste de correlação linear simples, em que foi obtido o coeficiente de correlação linear de Pearson $(\boldsymbol{r})$. Ambos os testes foram realizados com o auxílio do programa BioEstat 5.0.

\section{RESULTADOS E DISCUSSÕES}

\subsection{Condições meteorológicas dos sítios experimentais}

A Tabela 1 apresenta as médias dos valores registrados durante os períodos sazonais chuvoso (março), de transição (julho) e menos chuvoso (setembro), para as variáveis conteúdo volumétrico de água no solo, temperatura do solo e precipitação pluviométrica para os sítios PPBio e ESECAFLOR, situados na FLONA de Caxiuanã, PA.

A variável precipitação (PRP), não apresentou variação significativa $(\mathrm{p}>0,05)$ entre as áreas, somente entre os períodos chuvoso e menos chuvoso. Os valores médios obtidos para a precipitação no período chuvoso foram maiores que a média climatológica, já no período de transição (julho) ocorreu o inverso. Conforme Rodrigues et al. (2011), durante o ano de 2009, choveu mais do que a média climatológica no mês de março, enquanto no mês de julho, a precipitação ficou abaixo da média histórica. A estação chuvosa de 2009, estava sob a influência do fenômeno La Niña, que iniciou-se no segundo semestre de 2008. E na época seca do ano de 2009, as condições termais das águas do Pacífico central apontavam para o início de mais um evento de El Niño, que atingiu seu pico em dezembro de 2009, influenciando nas reduções de chuvas na Amazônia Oriental.

O maior e o menor valor médio $\left(0,38\right.$ e $\left.0,06 \mathrm{~mL} \mathrm{~m}^{-2}\right)$ para o conteúdo volumétrico de água no solo foram registrados no período chuvoso na parcela CI do experimento PPBio e no período menos chuvoso da parcela $\mathrm{B}$ do experimento ESECAFLOR, respectivamente (Tabela 1). De forma geral, os valores obtidos para essa variável confirmam a eficiência do processo de exclusão das águas pluviais realizado neste experimento e corroboram com os encontrados por Rodrigues et al. (2011).

Costa et al. (2006), estudando o Conteúdo Volumétrico de Água no Solo (CVAS) na área do experimento ESECAFLOR, também encontraram menores valores para a parcela de exclusão, quando comparados com os valores obtidos para a área

Tabela 1: Valores médios do conteúdo de água no solo (CVAS) na profundidade $0-30 \mathrm{~cm}$, da temperatura (T) do solo nas profundidades $5,10,20$ e $30 \mathrm{~cm}$ e da precipitação (PRP).

\begin{tabular}{|c|c|c|c|c|}
\hline VARIÁVEIS & Área & Chuvoso & Transição & Menos chuvoso \\
\hline \multirow{2}{*}{ CVAS (mL.m-2) } & PPBio & $0,38 \mathbf{a A}$ & $0,38 \mathbf{a A}$ & $0,25 \mathbf{b A}$ \\
\hline & ESECAFLOR & $0,10 \mathbf{a B}$ & $0,08 \mathbf{b B}$ & $0,06 \mathbf{c B}$ \\
\hline \multirow{2}{*}{ T $5 \mathrm{~cm}\left({ }^{\circ} \mathrm{C}\right)$} & PPBio & $25,5 \mathbf{a B}$ & $25,2 \mathbf{a B}$ & $25,4 \mathbf{a B}$ \\
\hline & ESECAFLOR & $26,5 \mathbf{b A}$ & $26,2 \mathbf{b A}$ & $27,2 \mathbf{a A}$ \\
\hline \multirow{2}{*}{ T $10 \mathrm{~cm}\left({ }^{\circ} \mathrm{C}\right)$} & PPBio & $25,5 \mathbf{a B}$ & $25,2 \mathbf{c B}$ & $25,4 \mathbf{a b B}$ \\
\hline & ESECAFLOR & $26,5 \mathbf{a A}$ & $26,1 \mathbf{b A}$ & $27,1 \mathbf{c A}$ \\
\hline \multirow{2}{*}{ T $20 \mathrm{~cm}\left({ }^{\circ} \mathrm{C}\right)$} & PPBio & $25,5 \mathbf{a B}$ & $25,1 \mathbf{c B}$ & $25,5 \mathbf{a b B}$ \\
\hline & ESECAFLOR & $26,5 \mathbf{a A}$ & $26,5 \mathbf{a A}$ & $27,3 \mathbf{b A}$ \\
\hline \multirow{2}{*}{ T $30 \mathrm{~cm}\left({ }^{\circ} \mathrm{C}\right)$} & PPBio & $25,6 \mathbf{a B}$ & $25,2 \mathbf{b B}$ & $25,5 \mathbf{a b B}$ \\
\hline & ESECAFLOR & $26,5 \mathbf{a A}$ & $26,2 \mathbf{b A}$ & $27,1 \mathbf{c A}$ \\
\hline \multirow{2}{*}{ PRP (mm) } & PPBio & $14,2 \mathbf{a A}$ & $1,3 \mathbf{b A}$ & $1,9 \mathbf{b A}$ \\
\hline & ESECAFLOR & $16,8 \mathbf{a A}$ & $2,9 \mathbf{b A}$ & $1,9 \mathbf{b A}$ \\
\hline
\end{tabular}

OBS: Médias com letras iguais, minúscula na horizontal e maiúscula na vertical, não diferem entre si pelo teste de Tukey. 
controle nos períodos chuvoso e menos chuvoso. Esse resultado evidencia a forte influência da estrutura de exclusão da água no efeito da seca na floresta. Santos et al. (2011), estudando a variação da umidade do solos nos anos de La Niña (2008) e El Niño (2006) na área da FLONA de Caxiuanã, verificaram que no primeiro, os valores para a umidade foram maiores quando comparados com o ano El Niño.

O maior valor médio para a temperatura do solo $(27,3$ ${ }^{\circ} \mathrm{C}$ ) foi registrado no período menos chuvoso na área do ESECAFLOR, a uma profundidade $20 \mathrm{~cm}$. As temperaturas médias obtidas na área do PPBio foram sempre menores que as obtidas para a área do ESECAFLOR, porém a variação da temperatura do solo teve o mesmo padrão de variação (Tabela 1). Santos et al. (2011) estudando a variação da temperatura do solo da FLONA de Caxiuanã em anos de La Niña e El Niño, registrou os maiores valores no ano de El Niño.

\subsection{Bactérias e fungos}

As contagens das populações de bactérias e fungos nas profundidades de 0-5, 5-10, 10-20 e 20-30 cm e nos períodos chuvoso, de transição e menos chuvoso são apresentados na
Tabela 2. A população de bactérias foi maior que a população de fungos, tanto na área do PPBio, quanto na área do ESECAFLOR, sendo o maior valor médio de UFC para bactérias (196 x 10 $\mathrm{UFC} / \mathrm{g}$ de solo) registrado no período de transição e na parcela CI do PPBio, e o maior valor médio de UFC para fungos (124 $\mathrm{x} 10^{2} \mathrm{UFC} / \mathrm{g}$ de solo) encontrado no período menos chuvoso, na mesma área. Em ambos os casos os valores se referem à primeira camada do solo $(0-5 \mathrm{~cm})$. Conforme Trabulsi e Alterthum (2005), Tortora et al. (2005), Moreira e Siqueira (2006), Pérezde-Mora et al. (2006) e Paul (2007), as populações de bactérias e fungos são maiores nos primeiros centímetros do solo devido à elevada concentração de matéria orgânica presente nessa faixa.

Quando comparados os resultados dos sítios estudados (Tabela 2), nota-se que as contagens de fungos e bactérias foram diferentes. Isso indica que os menores valores registrados para o conteúdo de água no solo (Tabela 1), ocasionados pela exclusão da precipitação na parcela B do ESECAFLOR influenciaram a população microbiana. Os estudos de Moreira et al. (2002), Zilli et al. (2003), Cattanio et al. (2008), Osaki e Netto (2009), Lopes et al. (2011), indicam que a quantidade, a qualidade do material orgânico e o teor de umidade do ambiente são as principais variáveis responsáveis pela dinâmica dos microrganismos no solo.

Tabela 2: Unidades Formadoras de Colônias (UFCs) médias para a população de bactérias e fungos do solo sob floresta primária (PPBio) e do solo submetido ao estresse hídrico (ESECAFLOR), em diferentes profundidades e regimes pluviométrico.

\begin{tabular}{|c|c|c|c|c|c|c|c|c|c|}
\hline Períodos & Áreas & $0-5 \mathrm{~cm}$ & & $5-10 \mathrm{~cm}$ & & $\begin{array}{c}10-20 \\
\mathrm{~cm}\end{array}$ & & $\begin{array}{c}20-30 \\
\mathrm{~cm}\end{array}$ & \\
\hline & & & & BACTI & RIAS ( & ${ }^{4} \mathrm{UFC} / \mathrm{g}$ & & & \\
\hline \multirow[b]{2}{*}{$\mathrm{CH}$} & PPBio & $120 \mathbf{a b}$ & & $81 \mathbf{a}$ & & $60 \mathbf{a}$ & & $18 \mathbf{a}$ & \multirow[b]{2}{*}{$<0,05$} \\
\hline & ESECAFLOR & $160 \mathrm{~A}$ & NS & $107 \mathbf{A}$ & NS & $87 \mathbf{A}$ & $<0,05$ & $68 \mathrm{~A}$ & \\
\hline \multirow{2}{*}{$\mathrm{TR}$} & PPBio & $196 \mathbf{a}$ & \multirow{2}{*}{$<0,05$} & $61 \mathbf{a}$ & \multirow{2}{*}{ NS } & $25 \mathbf{b}$ & \multirow{2}{*}{$<0,05$} & $20 \mathbf{a}$ & \multirow{2}{*}{ NS } \\
\hline & ESECAFLOR & $84 \mathbf{B}$ & & $57 \mathbf{B}$ & & 37 B & & $24 \mathbf{B}$ & \\
\hline \multirow{2}{*}{$\mathrm{MC}$} & PPBio & $95 \mathbf{b}$ & \multirow{2}{*}{ NS } & $32 \mathbf{b}$ & \multirow{2}{*}{ NS } & $25 \mathbf{b}$ & \multirow{2}{*}{$<0,05$} & $18 \mathbf{a}$ & \multirow{2}{*}{$<0,05$} \\
\hline & ESECAFLOR & $101 \mathbf{B}$ & & 54 B & & $44 \mathrm{BC}$ & & $43 \mathrm{C}$ & \\
\hline & & \multicolumn{8}{|c|}{ FUNGOS $\left(10^{2} \mathrm{UFC} / \mathrm{g}\right)$} \\
\hline \multirow{2}{*}{$\mathrm{CH}$} & PPBio & $73 \mathbf{b}$ & & $43 \mathbf{a}$ & & $27 \mathbf{a}$ & & $6 \mathbf{a}$ & \multirow{2}{*}{$<0,05$} \\
\hline & ESECAFLOR & $55 \mathrm{~B}$ & NS & $40 \mathrm{~A}$ & NS & $20 \mathbf{B}$ & $<0,05$ & $15 \mathbf{B}$ & \\
\hline \multirow[b]{2}{*}{ TR } & PPBio & $61 \mathbf{b}$ & \multirow[b]{2}{*}{ NS } & $23 \mathbf{b}$ & \multirow[b]{2}{*}{$<0,05$} & $20 \mathrm{c}$ & & $14 \mathbf{b}$ & \multirow[b]{2}{*}{$<0,05$} \\
\hline & ESECAFLOR & $51 \mathbf{A}$ & & $39 \mathbf{A}$ & & $23 \mathrm{~A}$ & $<\mathbf{0 , 0 5}$ & $11 \mathrm{~A}$ & \\
\hline \multirow{2}{*}{$\mathrm{MC}$} & PPBio & $124 \mathbf{a}$ & \multirow{2}{*}{$<0,05$} & 53 a & & $37 \mathbf{b}$ & NS & 9 ac & \multirow{2}{*}{$<0,05$} \\
\hline & ESECAFLOR & $79 \mathbf{A}$ & & $43 \mathbf{A B}$ & NS & $35 \mathbf{A B}$ & 1. & $21 \mathrm{~A}$ & \\
\hline
\end{tabular}

OBS: As letras minúsculas (PPBio) e maiúscula (ESECAFLOR) informam se houve diferença significativa entre os períodos sazonais estudados. Os números centrais informam se houve diferença significativa entre os sítios estudados. Médias com letras iguais não diferem entre si pelo teste de Tukey. NS - diferença não significativa ( $\mathrm{p}>0,05), \mathrm{CH}$ - período chuvoso, TR - período de transição e MC - período menos chuvoso. 
As respostas das contagens da população de fungos entre os períodos sazonais apresentaram diferença significativa, principalmente entre os períodos: chuvoso e menos chuvoso nas duas as áreas experimentais. Para as contagens de bactérias, isso é válido apenas para a camada sub-superficial $(05-10 \mathrm{~cm})$ (Tabela 2). Na área do ESECAFLOR, as contagens de fungos apresentaram variação entre os períodos sazonais e as contagens de bactérias, no geral, foram maiores no período chuvoso e se mantiveram relativamente estáveis nos períodos de transição e menos chuvoso. Na área do PPBio, as contagens de bactérias foram maiores no período de transição e tiveram seus valores mínimos no período menos chuvoso; já para as contagens de fungos, os maiores valores foram identificados no período menos chuvoso, principalmente nas camadas superficial e subsuperficial do solo.

Sobre isso Moreira e Siqueira (2006) explicam que a água, em conjunto com a temperatura, influi na atividade enzimática, favorecendo o metabolismo microbiano. Neste sentido, determinadas características fisiológicas das células microbianas podem ter sido ativadas no período chuvoso, no caso das bactérias, e no período menos chuvoso, no caso dos fungos, pois o período chuvoso apresentou os maiores valores de conteúdo de água no solo $\left(0,382 \mathrm{~mL} . \mathrm{m}^{-2}\right)$ e os menores valores de temperaturas $\left(27,6^{\circ} \mathrm{C}\right)$, para ambas as áreas.

Silva et al. (2010) e Rodrigues et al. (2011) estudaram a população microbiana do solo na área da FLONA de Caxiuanã-PA e encontraram que o padrão de distribuição da população de bactérias e fungos, em geral, diminui com a profundidade devido à deficiência do material orgânico que tende a decrescer conforme a profundidade. Porém, no solo submetido ao estresse hídrico, os autores identificaram que a população de bactérias apresentou comportamento irregular, sendo identificados altas contagens bacterianas em camadas mais profundas. Vianal et al. (2010) estudando a população microbiana do solo de Caxiuanã, PA também encontraram relação da temperatura do solo com as contagens dos microrganismos.

As contagens da população de fungos e bactérias, em ambas as áreas e nos diferentes períodos sazonais, apresentaram valores decrescentes conforme o aumento da profundidade (Tabela 3). De acordo com Amarante et al. (2010), é comum as populações de microrganismos do solo diminuírem nas maiores profundidades, uma vez que estes apresentam forte correlação com os fatores abióticos do solo, em especial a matéria orgânica, que por sua vez, é mais abundante nas primeiras camadas do solo. Osaki e Netto (2009) corroboram com tal afirmação e ressaltam que a camada $0-5 \mathrm{~cm}$ é a que mais favorece o desenvolvimento dos microrganismos.

\subsection{Nitrato e Amônio}

Os teores de nitrato $\left(\mathrm{N}-\mathrm{NO}_{3}{ }^{-}\right)$e amônio $\left(\mathrm{N}^{-\mathrm{NH}_{4}}{ }_{4}^{+}\right)$e os valores de umidade do solo nas camadas de 0-5, 5-10, 10-20 e 20-30 cm estão apresentados na Tabela 4. Os teores de nitrato foram maiores que os teores de amônio e variaram entre 7,08 a $71,79 \mathrm{mg} \mathrm{kg}^{-1}$, na área do PPBio e entre 5,95 a 19,16 mg $\mathrm{kg}^{-1}$, na área do ESECAFLOR. Os teores de nitrato foram diferentes estatisticamente $(\mathrm{p}<0,05)$, quando comparadas com as profundidades de coleta (Tabela 5), os períodos sazonais e as áreas estudadas (Tabela 4). Os maiores teores foram encontrados na área do PPBio e no período chuvoso.

A maioria das plantas tem preferência pelo íon nitrato, por isso é comum seu teores serem inferiores aos teores de amônio encontrados (Martinelli, 2003; Araújo et al., 2004), o que não ocorreu no presente estudo. Tal resultado se justifica

Tabela 3: Teste ANOVA para a determinação da variação dos valores de UFC de fungos e bactérias nas profundidades estudadas.

\begin{tabular}{|c|c|c|c|c|c|}
\hline \multirow{4}{*}{ Período } & \multirow{4}{*}{$\begin{array}{l}\text { Prof. } \\
(\mathrm{cm})\end{array}$} & Bactérias & Fungos & Bactérias & Fungos \\
\hline & & \multicolumn{4}{|c|}{$\left(10^{4}\right.$} \\
\hline & & $\left(10^{4} \mathrm{UFC} / \mathrm{g}\right)$ & $\left(10^{2} \mathrm{UFC} / \mathrm{g}\right)$ & $\mathrm{UFC} / \mathrm{g})$ & $\left(10^{2} \mathrm{UFC} / \mathrm{g}\right)$ \\
\hline & & \multicolumn{2}{|c|}{ PPBio } & \multicolumn{2}{|c|}{ ESECAFLOR } \\
\hline \multirow{4}{*}{ Chuvoso } & $00-05$ & $120 \mathrm{a}$ & $73 \mathbf{a}$ & $160 \mathbf{a}$ & $55 \mathbf{a}$ \\
\hline & $05-10$ & $81 \mathbf{a}$ & $43 \mathbf{a b}$ & $107 \mathbf{a b}$ & $40 \mathrm{a}$ \\
\hline & $10-20$ & $60 \mathbf{b}$ & $27 \mathbf{b}$ & 87 bc & $20 \mathbf{b}$ \\
\hline & $20-30$ & $18 \mathrm{c}$ & $6 \mathrm{c}$ & $68 \mathbf{c}$ & $15 \mathbf{b}$ \\
\hline \multirow{4}{*}{ Transição } & $00-05$ & $196 \mathbf{a}$ & $61 \mathbf{a}$ & $84 \mathbf{a}$ & $51 \mathbf{a}$ \\
\hline & $05-10$ & $61 \mathbf{b}$ & $23 \mathbf{b}$ & $57 \mathbf{a b}$ & $39 \mathbf{a b}$ \\
\hline & $10-20$ & $25 \mathrm{c}$ & $20 \mathbf{b}$ & 37 bc & $23 \mathbf{b}$ \\
\hline & $20-30$ & $20 \mathrm{c}$ & $14 \mathbf{b}$ & 24 bc & $11 \mathrm{c}$ \\
\hline \multirow{4}{*}{$\begin{array}{l}\text { Menos } \\
\text { chuvoso }\end{array}$} & $00-05$ & $95 \mathbf{a}$ & $124 \mathbf{a}$ & $101 \mathbf{a}$ & $79 \mathbf{a}$ \\
\hline & $05-10$ & 32 b & $53 \mathbf{b}$ & 54 b & $43 \mathbf{a}$ \\
\hline & $10-20$ & $25 \mathrm{bc}$ & $37 \mathbf{b c}$ & $44 \mathrm{~b}$ & $35 \mathbf{a b}$ \\
\hline & $20-30$ & $18 \mathbf{c}$ & $9 \mathbf{d}$ & $43 \mathbf{b}$ & $21 \mathbf{b}$ \\
\hline
\end{tabular}

OBS: Médias com letras iguais não diferem entre si pelo teste de Tukey. 
Tabela 4: Teores médios de Nitrato, Amônio e Umidade obtidos para o solo sob floresta primária (PPBio) e para o solo submetido ao estresse hídrico (ESECAFLOR), em diferentes profundidades e regimes pluviométrico.

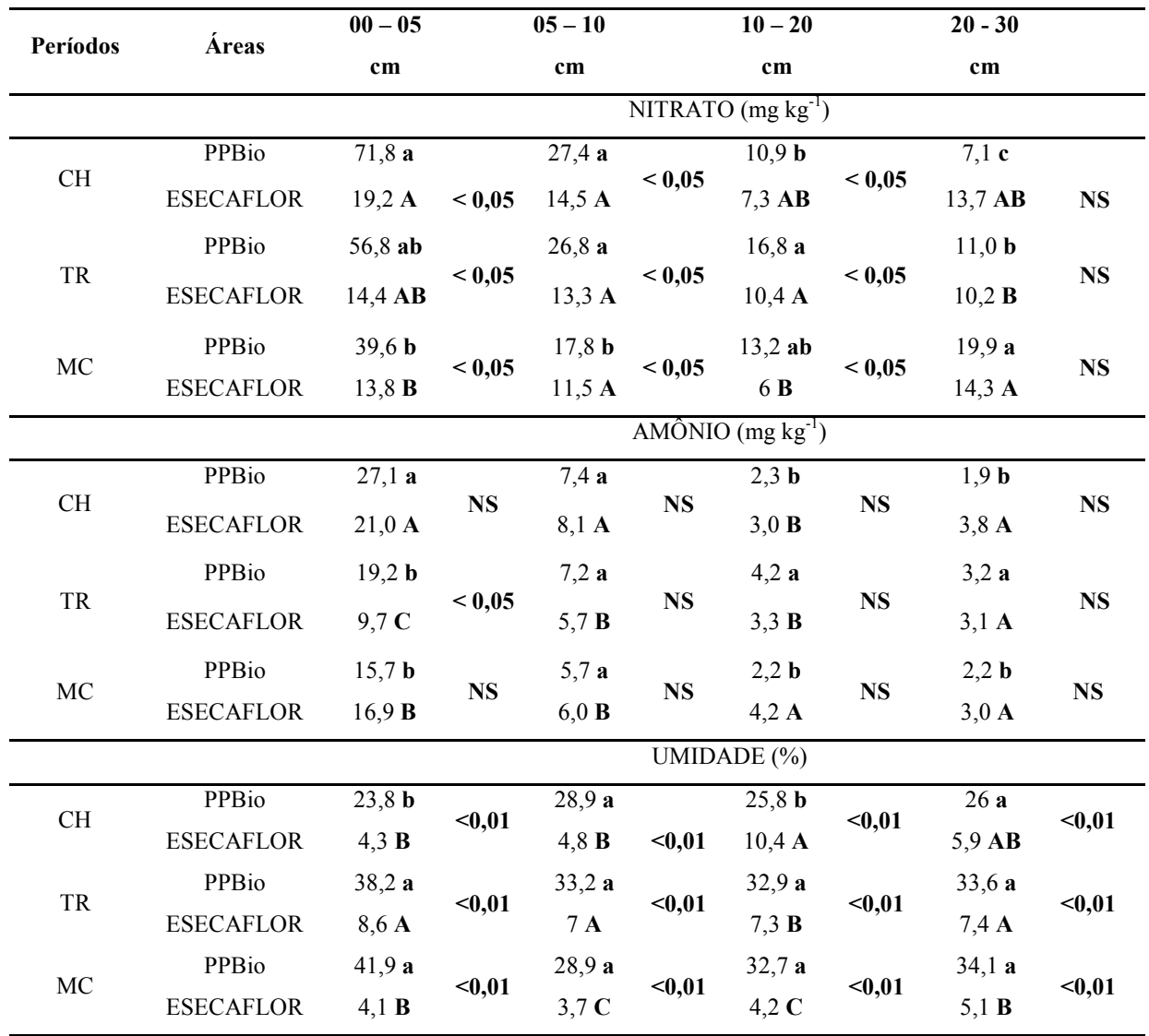

OBS: As letras minúsculas (PPBio) e maiúscula (ESECAFLOR) informam se houve diferença significativa entre os períodos sazonais estudados. Os números centrais informam se houve diferença significativa entre os sítios estudados. Médias com letras iguais não diferem entre si pelo teste de Tukey. NS - diferença não significativa ( $\mathrm{p}>0,05), \mathrm{CH}$ - período chuvoso, TR - período de transição e MC - período menos chuvoso.

pela fato do amônio, em determinadas condições ambientais, ser rapidamente oxidado a $\mathrm{NO}_{3}$, numa reação mediada por bactérias autotróficas, e elevar os teores desse íon no solo (Neill et al., 1997; Britto e Kronzucker, 2002).

Em muitos estudos sobre nitrato e amônio em solos tropicais, são relatados maiores teores para o amônio (Venzke Filho et al., 2004; Carmo et al., 2005; Dias, 2008). Para Dias (2008), a disponibilidade do amônio pode ser influenciada pela natureza do solo e pelas variáveis: temperatura, capacidade de retenção de água, aeração, $\mathrm{pH}$, que por sua vez afetam a atividade de microrganismos responsáveis pela mineralização do nitrogênio. É possível que a quantidade de microrganismos nitrificantes e as condições ambientais da FLONA de Caxiuanã favoreçam o processo de nitrificação.

A redução dos teores de nitrato, conforme o aumento da profundidade, provavelmente está relacionada à quantidade do material vegetal, que diminui no decorrer do perfil do solo e às condições ambientais que desfavorecem a atividade microbiana
(Tabela 5). Devido à sua carga elétrica, o amônio não costuma sofrer influência do processo de lixiviação; é por isso também, que não raro, é possível encontrar maiores teores de amônio no período sazonal mais chuvoso.

$\mathrm{Na}$ área do PPBio, a variação vertical do nitrato foi mais acentuada, ao contrário da área do ESECAFLOR, onde observou-se que as variações foram mais suaves, indicando a influência do processo de lixiviação na primeira área, principalmente no período chuvoso e transição (Tabela 5). Cabe ressaltar que os painéis instalados no ESECAFLOR desde 2002, interceptam $50 \%$ das águas pluviais, e que por isso, nos meses de maiores precipitação na região, pode também estar ocorrendo o processo de lixiviação do nitrato nessa área.

\section{CONCLUSÕES}

As variáveis micrometeorológicas sofreram influência dos fenômenos El Niño e La Niña e os menores valores 
Tabela 5: Teste ANOVA para a determinação da variação dos teores de nitrato e amônio e dos valores de umidade nas profundidades estudadas.

\begin{tabular}{cccccccc}
\hline Período & $\begin{array}{c}\text { Prof. } \\
(\mathrm{cm})\end{array}$ & $\begin{array}{c}\text { Nitrato } \\
\left(\mathrm{mg} \mathrm{kg}^{-1}\right)\end{array}$ & $\begin{array}{c}\text { Amônio } \\
\left(\mathrm{mg} \mathrm{kg}^{-1}\right)\end{array}$ & $\begin{array}{c}\text { Umidade } \\
(\%)\end{array}$ & $\begin{array}{c}\text { Nitrato } \\
\left(\mathrm{mg} \mathrm{kg}^{-1}\right)\end{array}$ & $\begin{array}{c}\text { Amônio } \\
\left(\mathrm{mg} \mathrm{kg}^{-1}\right)\end{array}$ & $\begin{array}{c}\text { Umidade } \\
(\%)\end{array}$ \\
\hline \multirow{5}{*}{ Chuvoso } & $05-10$ & $27,4 \mathbf{b}$ & $7,4 \mathbf{b}$ & $28,9 \mathbf{a}$ & $14,5 \mathbf{a}$ & $8,1 \mathbf{b}$ & $4,8 \mathbf{a}$ \\
& $10-20$ & $10,9 \mathbf{c}$ & $2,3 \mathbf{c}$ & $25,9 \mathbf{a}$ & $7,3 \mathbf{b}$ & $3,4 \mathbf{c}$ & $10,4 \mathbf{b}$ \\
& $20-30$ & $7,1 \mathbf{c}$ & $1,9 \mathbf{c}$ & $26,0 \mathbf{a}$ & $13,7 \mathbf{b}$ & $3,8 \mathbf{c}$ & $5,9 \mathbf{a}$ \\
\hline \multirow{4}{*}{ Transição } & $05-10$ & $26,8 \mathbf{b}$ & $7,2 \mathbf{b}$ & $33,2 \mathbf{a}$ & $13,3 \mathbf{a}$ & $5,7 \mathbf{b}$ & $7,0 \mathbf{a}$ \\
& $00-05$ & $56,8 \mathbf{a}$ & $19,2 \mathbf{a}$ & $38,2 \mathbf{a}$ & $14,4 \mathbf{a}$ & $9,7 \mathbf{a}$ & $8,6 \mathbf{a}$ \\
& $10-20$ & $16,3 \mathbf{c}$ & $4,2 \mathbf{b}$ & $32,9 \mathbf{a}$ & $10,4 \mathbf{a}$ & $3,3 \mathbf{b}$ & $7,3 \mathbf{a}$ \\
& $20-30$ & $11,0 \mathbf{c}$ & $3,2 \mathbf{c}$ & $33,6 \mathbf{a}$ & $10,2 \mathbf{a}$ & $3,1 \mathbf{b}$ & $7,4 \mathbf{a}$ \\
\hline \multirow{4}{*}{ Menos } & $00-05$ & $39,6 \mathbf{a}$ & $15,7 \mathbf{a}$ & $41,9 \mathbf{a}$ & $13,8 \mathbf{a}$ & $16,88 \mathbf{a}$ & $4,1 \mathbf{a}$ \\
chuvoso & $05-10$ & $17,8 \mathbf{b}$ & $5,7 \mathbf{b}$ & $28,9 \mathbf{a}$ & $11,5 \mathbf{a}$ & $6,04 \mathbf{b}$ & $3,7 \mathbf{a}$ \\
& $10-20$ & $13,2 \mathbf{b}$ & $2,2 \mathbf{c}$ & $32,7 \mathbf{a}$ & $6,0 \mathbf{b}$ & $4,24 \mathbf{b}$ & $4,2 \mathbf{a}$ \\
& $20-30$ & $19,9 \mathbf{b}$ & $2,2 \mathbf{c}$ & $34,1 \mathbf{a}$ & $14,3 \mathbf{a}$ & $3,02 \mathbf{b}$ & $5,1 \mathbf{a}$ \\
\hline
\end{tabular}

OBS: Médias com letras iguais não diferem entre si pelo teste de Tukey.

registrados, quanto ao conteúdo de água no solo, na parcela B do ESECAFLOR, são consequência do menor aporte de água que entra no sistema devido a interceptação dos painéis instalados. A microbiota apresentou sensibilidade respondendo as mudanças do microclima e também em relação às áreas experimentais. A umidade do solo é a variável que têm principal relação de dependência com as variações observadas nas contagens das populações de fungos e bactérias, e sobre os teores de nitrato e amônio. Os teores de nitrato foram sempre maiores que os teores de amônio. Os teores de nitrato foram influenciados pelo processo de lixiviação e o amônio, devido sua carga elétrica, não mostrou variação significativa quanto a este processo.

\section{AGRADECIMENTOS}

Ao Conselho Nacional de Desenvolvimento Científico e Tecnológico - CNPq, ao Projeto Bioclima-CNPq/Universal (2009-2010), ao Programa de Pesquisa em Biodiversidade - PPBio, ao Projeto ESECAFLOR, ao Programa em Larga Escala da Biosfera-Atmosfera na Amazônia (LBA) e ao Projeto PRONEX/FAPESPA/CNPq "Rede de Mudanças Climáticas e Ambientais do Pará: uma perspectiva de estudos integrados". Os resultados deste artigo fazem parte da Dissertação de Mestrado do $1^{a}$ Autor, junto ao Programa de Pós Graduação em Ciências Ambientais da Universidade Federal do Pará (PPGCA/UFPA).

\section{REFERÊNCIAS BIBLIOGRÁFICAS}

ALMEIDA, S. S. et al. Diversidade florística de uma comunidade arbórea na Estação Científica "Ferreira Penna", em Caxiuanã (Pará). Boletim do Museu Paraense Emilio Goeldi. - Série Botânica, v, 9, p.99-188, 1993.

AMARANTE, C. B.; et al. Diversidade microbiana em solos de Terra Preta Arqueológica. Enciclopédia Biosfera, v. 6, p. 1-10, 2010.

ARAÚJO, A. R. et al. Movimentação de nitrato e amônio em colunas de solo. Ciência e Agrotécnologia, v. 28, p.537541, 2004.

BRITTO, D. T.; KRONZUCKER, H. J. NH4 + toxicity in higher plants: a critical review. Brazilian Journal of Plant Physiology, Campos dos Goytacazes, v. 9, p. 567584, 2002.

CARMO, J. B. et al. Nitrogen dynamics during till and no-till pasture restoration sequences in Rondônia, Brazil. Nutrient Cycling in Agroecosystems, v. 71, p.213-225, 2005.

CATTANIO, J. H. et al. Organic material decomposition and nutrient dynamics in a leguminous tree-enriched mulch system in Amazon. Revista Brasileira de Ciência do Solo, v. 32, p. 1073-1086, 2008.

CHAPIN, F. S. et al. Principles of terrestrial Ecosystem ecology. Nova York: Springer, 2002, 455 p.

CLARK, F. E. Agar-plate method for total microbial count. In: Methods of soil analysis. Madison, American Society of Agronomy, 1965, p.1460-1466.

COSTA, A. C. L. et al. Estudos Hidrometeorológicos em uma Floresta Tropical Chuvosa na Amazônia - Projeto ESECAFLOR. Revista Brasileira de Meteorologia, v. 21, p. 283-290, 2006.

COSTA, A. C. L. et al. Experimento Esecaflor-LBA em Caxiuanã. In: LISBOA, P. L. B. (Org.) Caxiuanã: desafios 
para a conservação de uma Floresta Nacional na Amazônia. Ed. MPEG, Belém, 2009, p. 45-91.

DIAS, J. D. Dinâmica do amônio e nitrato em solos consorciados com plantios de paricá (schizolobium amazonicum) em Arora do Para, Pará. 2008. 88 f. Dissertação (Mestrado em Ciências Ambientais) Universidade Federal do Pará, Belém, 2008.

FEARNSIDE, P. M. A vulnerabilidade da floresta amazônica perante as mudanças climáticas. Oecologia Brasiliensis, v. 13, p. 609-618, 2009.

FISHER, R. A. et al. The response of an Eastern Amazonian rain forest to drought stress: results and modelling analyses from a throughfall exclusion experiment. Global Change Biology, v. 13, p. 1-18, 2007.

FURTINI NETO, A. E. Fertilização em reflorestamento com espécies nativas. In: Nutrição e Fertilização Florestal. Piracicaba: IPEF, 2005, p. 351-383.

GOBERNA, M. INSAM, H. KLAMMER, S.; PASCUAL, J. A.; SÁNCHEZ, J. Microbial community structure at different depths in disturbed and undisturbed semiarid Mediterranean forest soil. Microbial Ecology, v. 5 , p. 315-326, 2005.

INPA. Sobre o PPBio...!. 2007. Disponível em: <http://ppbio. inpa.gov.br/Port/sobreppbio/index_html\#oque>.Acesso em: 21 de mar de 2011.

KEENEY, D. R. Nitrogen: availability indices. In: PAGE, A. L. Methods of soil analysis. Madison, Journal of American Society of Agronomy, p. 711-733. 1996.

KERN, D. C. Geoquímica e pedoquímica em sítios arqueológicos com terra preta na Floresta Nacional de Caxiuanã (Portel- PA). 1996, 119f., Tese de Doutorado, Universidade Federal do Pará, Belém, 1996.

LOPES, E. L. N. et al. Microbial biomass and soil chemical properties under different land use systems in northeastern Pará. Revista. Brasileira de Ciência do Solo. v. 35, n. 4, p. 1127-1139, 2011.

LUIZAO, F. J. Ciclos de nutrientes na Amazônia: respostas às mudanças ambientais e climáticas. Ciência e Cultura, $v$. 59, n. 3, p. 31-36, 2007.

LUIZÃO, F. J. Litter production and mineral element input to the forest floor in a Central Amazonian forest. GeoJournal, v. 19, p. 407-417, 1989.

MARENGO, J. A. et.al. Future change of temperature and precipitation extremes in South America as derived from the PRECIS regional climate modeling system. International Journal of Climatology, n. 29, p. 241 - 255, 2009.

MARTINELLI, L. A. Element interactions in Brazilian landscapes as influenced by human interventions. In: Scope 60: Interactions of the major biogeochemical cycles: Global change and human impacts. Islands Press, p.193210, 2003.
MEIR, P. et al. Effects of experimental drought on carbon cycling in an Eastern Amazon rain forest. In: Science Team Business Meeting 7, 2003. Proceedings...Results of Ecological Studies of LBA, Fortaleza: LBA/ECO, 2003. CD-ROM.

MOREIRA, A. et al. Eficiência de fontes e doses de fósforo na alfafa e centrosena cultivados em Latossolo amarelo. Pesquisa Agropecuária Brasileira, v. 37, p. 1459 - 1466, 2002. MOREIRA, F. M. S.; SIQUEIRA, J. O. Microbiologia e Bioquímica do Solo. 2 ed. Lavras, UFLA, 2006, p.729.

NEILL, C. et al. Soil carbon and nitrogen stocks following forest clearing for pasture in the southwestern Brazilian Amazon. Ecological Applications, v. 7, p.1 216-1225, 1997.

NOBRE, C. A; SAMPAIO, G.; SALAZAR, L. Mudanças climáticas e a Amazônia. Ciência e Cultura, v. 59, p. 2227, 2007.

NOVAIS, R. F.; BARROS, N. F. Sustainable agriculture and forestry production systems on acid soils: phosphorus as a case study. In: Plant-soil interactions at low Ph: Sustainable agriculture and forestry productions. Campinas, Brazilian Soil Science Society, 1997, p. 314-320.

OSAKI, F.; NETTO, S. P. Flutuação da população de bactérias sob floresta ombrófila mista e povoamento de Pinus taeda L. Floresta, v. 39, p. 845-852, 2009.

PAUL, E.A. Soil Microbiology, Ecology and Biochemistry. Academic Press, 2007, 552p.

PÉREZ-DE-MORA, A, et al. Microbial community structure and function in a soil contaminated by heavy metals: effects of plant growth and different amendments. Soil Biology and Biochemistry, v. 38, p. 327-341, 2006.

RODRIGUES, H. J. B. et al. Variabilidade quantitativa de população microbiana associada às condições microclimáticas observadas em solo de floresta tropical húmida. Revista Brasileira de Meteorologia,v. 26, p. 629-638, 2011.

RUIVO, M. L. P. et al. Population and biodiversity in Amazon dark earths soils. In: RIOS, G. M e CAMARGO, S. M (Eds). Pueblos y paisajes antiguos de la selva tropical amazónica Colombiana, Universidade Nacional da Colombia, Bogotá - Tara - Xacum/Washington, 2006, p. 284-291.

RUIVO, M. L. P. et al. Propriedades do solo e fluxo de $\mathrm{CO}_{2}$ em Caxiuanã, Pará: experimento LBA-ESECAFLOR. In: KLEIN, E. L.; VASQUEZ, M. L.; COSTA, L. T. R. (Org.). Contribuições a geologia da Amazônia. Belém, Sociedade Brasileira de Geologia - Núcleo Norte, 2002, p. 291-299.

SANTOS, S. R. Q. et al. Regime térmico e hídrico do solo para área de floresta tropical em anos de El Niño e $L a$ Niña, Caxiuanã-PA: estudo de caso. Revista Brasileira de Meteorologia, v. 26, p. 367-374, 2011. 
SILVA JUNIOR, J .A. et al. Fluxos de $\mathrm{CO}_{2}$ do solo na Floresta Nacional de Caxiuanã, Pará, durante o experimento ESECAFLOR/LBA. Revista Brasileira de Meteorologia, v. 28, n. 1, p. 85-94, 2013.

SILVA, R. B. et al. Estudo das colônias de fungos e bactérias em solos de floresta tropical associada à variação das chuvas na região. In: XVI Congresso Brasileiro de Meteorologia, 2010. Anais da Sociedade Brasileira de Meteorologia, Belém, 2010. CD-ROM.

TORTORA, G. J. et al. Microbiology: an introduction. [S.1]: E. Pearson, 2005, [s.p.].

TRABULSI, L. R.; ALTERTHUM, F. Microbiologia. 4. ed. São Paulo: Atheneu, 2005. 717p.

VENZKE FILHO, S. P. et al. Root systems and soil microbial biomass under no-tillage system. Scientia Agricola, Piracicaba, v. 61, p. 529-537, 2004.
VIANAL, R. S. et al. Perfil de Temperatura do Solo Relacionado com a Variabilidade de Microorganismos em Floresta Tropical Úmida. In: XVI Congresso Brasileiro de Meteorologia, 16, 2010. Anais... Sociedade Brasileira de Meteorologia, Belém, 2010. CD-ROM.

YANG, J. E. et al. Simple spectrophotometric determination of nitrate in water, resin and soil extracts. Soil Science Society of America Journal, v. 62, p. 1108-1115, 1998.

ZILLI, J. E. et al. Diversidade microbiana como indicador de qualidade do solo. Cadernos de Ciência e Tecnologia, Brasília, v. 20, n. 3, p. 391-411, 2003. 